\title{
Prevalence of musculoskeletal disorders and their association with ergonomic physical risk factors among women working in tea gardens of Darjeeling district of West Bengal, India
}

\author{
Chakraborty S $\mathbf{S}^{1}$, Bhattacherjee $\mathbf{S}^{2}$, Mukherjee $\mathrm{A}^{3}$, Dasgupta $\mathbf{S}^{4}$ \\ ${ }^{1}$ Demonstrator, Department of Community Medicine, Bankura Sammilani Medical College, Bankura, \\ ${ }^{2}$ Associate Professor, ${ }^{3}$ Assistant Professor, ${ }^{4}$ Ex-Professor, Department of Community Medicine, North Bengal \\ Medical College, Darjeeling, West Bengal, India
}

\section{ABSTRACT}

Introduction: Work related musculoskeletal disorders (WRMSDs) is common among tea-plucking folks and may be attributed to the long duration of work in same posture, the load they carry while plucking and transporting the leaves to the nearest depot, improper job rotations and the difficult hilly terrains. The objective of this study was to determine the prevalence and pattern of musculoskeletal disorders among tea garden workers and to ascertain the risk factors for the same.

Methods: A cross-sectional study was conducted among 210 female tea garden workers employed in tea gardens of Darjeeling district using 30 cluster sampling design. Data on musculoskeletal morbidities were collected using Standard Nordic Musculoskeletal Questionnaire and ergonomic risk was assessed by Rapid Entire Body Assessment (REBA) worksheet. Study duration was from March 2017 to February 2018.

Results: Proportion of musculoskeletal disorders in past 12 months was $92.4 \%$ and in past seven days was $71.4 \%$. Upper extremities were the most commonly affected body part. Higher altitude, age, BMI, more duration in present job, history of work-related injuries and increased REBA risk assessment score were found to be significantly associated with musculoskeletal disorders.

Conclusion: Musculoskeletal morbidities among female tea garden workers of Darjeeling were found to be considerably high. Ergonomic mechanised assistance in tea plucking can reduce this proportion of MSD and thus may go a long way in reducing sickness absenteeism and increasing productivity.

Key words: Female, REBA employee assessment worksheet, Standard Nordic Musculoskeletal Questionnaire, Tea garden workers, Work related musculoskeletal disorders.

\section{Introduction}

n all aspects of tea production, consumption and export, India has emerged to be the world leader, mainly because it accounts for $31 \%$ of global production. ${ }^{1}$ Since the establishment of the first tea

DOI: https://doi.org/10.3126/ijosh.v11i1.35179

Date of submission: 24.02.2021

Date of acceptance: 30.03 .2021

\section{Corresponding Author}

Dr. Sumanta Chakraborty, MD (Community Medicine)

22/108, Raja Manindra Road, Kolkata,

West Bengal, India, Pin code - 700037

Phone- 09432647678

E-mail: sumanta.chakraborty9@gmail.com

ORCID ID: https://orcid.org/0000-0002-6644-9340 garden by the British East India Company in 1835, ${ }^{2}$ India has become the world's largest consumer of black tea with the domestic market consuming 911 million $\mathrm{kg}$ of tea during 2013-14, thereby, tea has almost become the staple beverage of every Indian household. India is ranked second in terms of production and fourth in terms of tea exports, and thereby tea industry contributes to $0.26 \%$ of India's GDP. ${ }^{3}$ India's tea plantations are largely grouped into two regions-North East India and South India. ${ }^{3}$ Darjeeling is famous globally for some of the best flavours of tea.

Work Related Musculoskeletal Disorder (WRMSDs) are seldom life threatening but they impair the quality of life

\section{(c) (1) (8)}

This journal is licensed under a Creative Commons AttributionNon Commercial 4.0 International License. 
of a large proportion of the adult population. It develops over time and may affect muscles, joints and tendons in all parts of the body. They can be episodic or chronic in nature and can also result from injury sustained in a work-related accident. They can progress from mild to severe disorders. ${ }^{4}$

Work-related disorders can develop in an occupational setting due to the physical tasks with which individuals carry out their normal work activities. WRMSDs are associated with work patterns that include fixed or constrained body positions, continual repetition of movements, force concentrated on small parts of the body, such as the hand or wrist and a pace of work that does not allow sufficient recovery between movements. Additionally, workplace psychosocial factors such as organisational culture, health and safety climate and human factors may create the conditions for WRMSDs to occur. Generally, none of these factors acts separately to cause WRMSDs. They more commonly occur as a result of a combination and interaction among them. ${ }^{5}$

The work of tea plucking is still being practised in a traditional manner without considering its adverse health effects. Long duration of work in same posture, the load they carry while plucking and transporting the leaves to the nearest depot, improper job rotations and the difficult hilly terrains may attribute to work related musculoskeletal disorders in the tea garden population. The tea plucking is traditionally a women centric activity with the men being employed for other activities but not tea plucking. There is dearth of published literature about WRMSDs among the tea garden workers working in the difficult terrains of Darjeeling where the chief economy rests on tea industry. Thereby, this study explores the pattern and prevalence of WRMSDs among the workers and also find out interplay of risk factors causing them.

The objectives of this study were to determine the proportion and pattern of musculoskeletal disorders and to ascertain the various risk factors associated with work related musculoskeletal disorders among women tea garden workers.

\section{Methods}

It was a descriptive cross-sectional study conducted in Darjeeling district of West Bengal. This district has 4 subdivisions - Darjeeling, Mirik, Kurseong and Siliguri and 9 Community Development Blocks. There are 137 notified tea gardens in Darjeeling district distributed among the four sub-divisions. Study duration was from March 2017 to February 2018. Women between 20-60 years of age working in tea gardens in the study area for at least 1 year were included in the study.

Sample size was estimated using single proportion formula for cross sectional studies considering the factors of: desired level of confidence, acceptable margin of error, relative precision (as finite population taken), design effect of the sampling technique, anticipated proportion of musculoskeletal disorders. ${ }^{6}$ Community based studies in North Indian context showing proportion of musculoskeletal disorders among tea garden workers are lacking. So a study conducted in Tamil Nadu among tea garden workers in 2016 was considered here, where $78.5 \%$ of tea garden workers had experienced musculoskeletal pain in past seven days. ${ }^{7}$ The anticipated proportion of musculoskeletal disorders among the study population thus will be taken as $78.5 \%$. Considering $95 \%$ level of confidence and $10 \%$ relative precision, the sample size will be calculated using the following formula:

$n=Z^{2}(1-\alpha / 2) P(1-P) / e^{2}$ where:

- $\quad Z(1-\alpha / 2)=1.96$ (at 95\% confidence interval)

- $\mathrm{P}=$ anticipated proportion of musculoskeletal disorders among tea garden workers (78.5\%)

- $\quad e=$ relative precision $(10 \%$ of 78.5$)$

Thus, the calculated sample size comes to be $\mathrm{n}=$ $(1.96) 2 \times 0.785 \times 0.215 /(0.10 \times 0.785)^{2}=105$

As cluster sampling was done, a design effect of 2 was considered. Thus sample size came out to be 210 .

Cluster sampling technique was applied to select the study subjects. Each tea garden of Darjeeling district was considered as 'cluster'. In the first stage list of all tea gardens of Darjeeling district was prepared with their respective population and cumulative population and 30 clusters (tea gardens) were identified using cluster sampling technique. In the second stage, from each selected cluster equal number of study subjects was included, thus cluster size will be 210/30 7

In an identified cluster which is a tea garden, list of all the women working as tea pluckers was prepared with the help of garden authorities. Seven women were selected by simple random sampling (without replacement) from the prepared sampling frame from each cluster. Their addresses were obtained beforehand from local health workers and they were 
interviewed at their household at mutually convenient time. If there are non-responders from the selected seven women in each cluster, rest of the women were selected again randomly from the previously prepared sampling frame in each village to complete the cluster size of seven.

Pre-designed pre-tested interview schedule consisting of background characteristics \& socio-demographic characteristics with Standard Nordic Musculoskeletal Questionnaire, Wong-Baker Pain assessment Tool, REBA employee assessment worksheet, and any relevant medical records/prescription was done. The instrument used in this study is the Standard Nordic Questionnaire (SNQ) which records musculoskeletal symptoms and screens for musculoskeletal disorders in an ergonomic context. ${ }^{9} \mathrm{SNQ}$ is a valuable tool in occupational health care service research as screening for musculoskeletal symptoms in occupational settings. ${ }^{10}$ REBA employee assessment worksheet is an ergonomic assessment tool which uses a systematic process to evaluate whole body postural MSD and risks associated with job tasks and was used in this study. ${ }^{10}$

The eligible women tea garden workers were interviewed using the pre-designed pretested schedule after obtaining informed written consent. The schedule was customised for the study with the help of the subject experts of the Department of Community Medicine of North Bengal Medical College. Musculoskeletal disorders are a diverse group of disorders regarding pathophysiology and as per World Health Organization (WHO), the burden of Musculoskeletal Disorders can be assessed in terms of problems associated with them which include pain, ache, discomfort, numbness or disability or in relation to the cause such as joint disease or trauma.

Data was collected by the researchers after translation, back-translation, and re-translation of the Standard Nordic Musculoskeletal Questionnaire, Wong-Baker Pain assessment Tool, REBA employee assessment worksheet with the help of language experts, followed by pre-testing among a convenience sample of 30 individuals attending the OPD of Kiran Chandra Tea Estate, Naxalbari, the rural field practice area of the Department of Community Medicine of North Bengal Medical College and Hospital.

Data were collected in predesigned and pretested schedule and handled with strict confidentiality.
Data were entered into Excel (Microsoft Inc.) and all calculations were done using IBM Statistical Package for the Social Sciences (SPSS) (Version 20.0, IBM). Data were analysed and presented using principles of descriptive and analytical statistics. Univariate logistic regression and multivariate logistic regression was carried out with the variables.

The study was conducted after the approval of the Institutional Ethics Committee of North Bengal Medical College, Darjeeling. Informed consent was obtained from all the study participants. Permission for the study was sought from the Tea board of India from its office in Kolkata and the Chief medical officer of health of Darjeeling district.

\section{Results:}

Women belonged to age group of more than 40 years of age were $97.5 \%$. Among all the participants $96.4 \%$ were working at an altitude of more than $500 \mathrm{~m}$ and $95 \%$ of workers belonged to BPL families were having musculoskeletal disorders. (Table 1)

Among overweight workers, $95.6 \%$ and of underweight, $95 \%$ workers had musculoskeletal disorders. Women having musculoskeletal disorders had pallor comprised 97.3\%. (Table 2)

Duration in present job, average working hours per day, last working day harvest, number of episodes of work-related injury in past 1 year and REBA score were found to be significant factors influencing the musculoskeletal disorders among women working in tea gardens of Darjeeling. (Table 3)

Prevalence of musculoskeletal disorders in past 12 months was $92.4 \%$ and in past 7 days was $71.4 \%$. Upper extremities were the most commonly affected body part. Elbow pain was the commonest in both past seven days ( $55.7 \%$ ) and past 12 months ( $82.4 \%)$. Elbow pain and low back pain seems to be more chronic in both past 7 days and past 12 months duration periods. (Table 4)

Those working at an altitude of 500 meters or less and aged less than 40 years were less likely of developing musculoskeletal disorders. Musculoskeletal disorders in women below poverty line (BPL) families is more likely, however; it was not found significant on univariate regression analysis. 
There was more likelihood of musculoskeletal disorders among women who were underweight, overweight or had pallor. But only being overweight was statistically significant predictor of musculoskeletal disorders on univariate logistic regression analysis.

Duration in present job, average working hours per day, last working day harvest, number of episodes of work-related injury in past 1 year and REBA score were found to be significant factors influencing the musculoskeletal disorders among women working in tea gardens of Darjeeling.

Tables 5, 6 and Figure 1 show three predictive models for predicting the musculoskeletal disorders among the women working in the tea gardens that were developed for the present study. Model 1 includes only the socioeconomic variables; Model 2 includes the socioeconomic and physical parameters related variable and Model 3 includes the ergonomic related variables in addition to the variables in Model 2.

Table 1: Socio-demographic risk factors of musculoskeletal diseases among study subjects $(\mathrm{N}=210)$

\begin{tabular}{|c|c|c|c|c|c|}
\hline \multirow{3}{*}{$\begin{array}{l}\text { Socio-demographic risk } \\
\text { factors }\end{array}$} & \multirow{3}{*}{$\begin{array}{c}\text { Total } \\
\mathbf{N}\end{array}$} & \multicolumn{2}{|c|}{ Musculoskeletal disorder } & \multirow{3}{*}{ COR $(95 \% \mathrm{Cl})$} & \multirow{3}{*}{ AOR $(95 \% \mathrm{Cl})$} \\
\hline & & Absent & Present & & \\
\hline & & $\mathbf{N}(\%)$ & $\mathrm{N}(\%)$ & & \\
\hline \multicolumn{6}{|l|}{ Age } \\
\hline$<40$ years & 92 & $13(14.1)$ & 79 (85.9) & ${ }^{*} 0.159(0.044-0.575)$ & \\
\hline$>=40$ years & 118 & $3(2.5)$ & $115(97.5)$ & 1.00 (Reference) & 1.00 (Reference) \\
\hline \multicolumn{6}{|l|}{ Altitude } \\
\hline$<500 \mathrm{~m}$ & 56 & $10(17.9)$ & $46(82.1)$ & *0.186 (0.064-0.541) & \\
\hline$>=500 \mathrm{~m}$ & 154 & $6(3.9)$ & $148(96.1)$ & 1.00 (Reference) & 1.00 (Reference) \\
\hline \multicolumn{6}{|l|}{ Socio-economic status } \\
\hline Below poverty line & 100 & $5(5)$ & $95(95)$ & $2.111(0.707-6.304)$ & \\
\hline Above poverty line & 110 & $11(10)$ & $99(90)$ & 1.00 (Reference) & 1.00 (Reference) \\
\hline
\end{tabular}

Table 2: Physical risk factors of musculoskeletal diseases among study subjects $(\mathrm{N}=210)$

\begin{tabular}{|c|c|c|c|c|c|}
\hline \multirow{2}{*}{$\begin{array}{l}\text { Physical risk } \\
\text { factors }\end{array}$} & Total & $\begin{array}{l}\text { Musculoskeletal } \\
\text { disease absent }\end{array}$ & $\begin{array}{l}\text { Musculoskeletal } \\
\text { disease present }\end{array}$ & \multirow[t]{2}{*}{ COR (95\% CI) } & \multirow[t]{2}{*}{ AOR (95\% Cl) } \\
\hline & $\mathbf{N}$ & $\mathrm{N}(\%)$ & $\mathbf{N}(\%)$ & & \\
\hline \multicolumn{6}{|l|}{ BMI } \\
\hline Underweight & 60 & $3(5)$ & $57(95)$ & $3.420(0.877-13.334)$ & \\
\hline Normal & 59 & $9(15.3)$ & $50(84.7)$ & 1.00 (Reference) & 1.00 (Reference) \\
\hline Overweight & 91 & $4(4.4)$ & 87 (95.6) & *3.195 (1.147-13.368) & \\
\hline \multicolumn{6}{|l|}{ Pallor } \\
\hline Negative & 60 & $12(20)$ & $48(80)$ & 1.00 (Reference) & 1.00 (Reference) \\
\hline Positive & 150 & $4(2.7)$ & 146 (97.3) & $1.396(0.500-3.900)$ & \\
\hline
\end{tabular}

Table 3: Ergonomic risk factors of musculoskeletal diseases among study subjects $(\mathrm{N}=210)$

\begin{tabular}{|c|c|c|c|c|c|c|}
\hline \multirow{3}{*}{ Ergonomic risk factors } & \multicolumn{4}{|c|}{ Musculoskeletal disorder } & \multirow{3}{*}{ COR $(95 \% \mathrm{Cl})$} & \multirow{3}{*}{$\operatorname{AOR}(95 \% \mathrm{Cl})$} \\
\hline & \multicolumn{2}{|c|}{ Absent } & \multicolumn{2}{|c|}{ Present } & & \\
\hline & Mean & SD & Mean & SD & & \\
\hline Duration in present job & 5.19 & 4.34 & 21.62 & 12.23 & $* 1.257(1.110-1.423)$ & *3.901(2.236-8.425) \\
\hline Average working hours per day & 9.63 & 0.81 & 8.71 & 0.91 & $0.320(0.161-0.635)$ & $1.457(0.414-5.125)$ \\
\hline Last working day harvest & 59.37 & 15.31 & 34.16 & 9.87 & ${ }^{*} 0.893(0.857-0.930)$ & ${ }^{*} 0.068(0.014-0.325)$ \\
\hline $\begin{array}{l}\text { Number of episodes of work } \\
\text { related injury in past } 1 \text { year }\end{array}$ & 1.31 & 1.30 & 5.01 & 3.27 & *2.291(1.530-3.431) & *3.279(1.367-8.768) \\
\hline REBA score & 3.69 & 1.35 & 6.36 & 2.62 & *2.040(1.284-3.242) & ${ }^{*} 7.263(1.214-13.456)$ \\
\hline Total & \multicolumn{2}{|c|}{$16(7.6 \%)$} & \multicolumn{2}{|c|}{$194(92.4 \%)$} & & \\
\hline
\end{tabular}


Table 4: Pattern of musculoskeletal pain in past 7 days and past 12 months among the study subjects $(\mathrm{N}=210)$

\begin{tabular}{ccc}
\hline Type of joint pain & Pattern in last 7 days & Pattern in last 12 months \\
\cline { 2 - 3 } $\mathbf{N}(\%)$ & $\mathbf{N}(\%)$ \\
\hline Neck pain & $31(14.8)$ & $78(37.1)$ \\
\hline Shoulder pain & $49(23.3)$ & $128(61.0)$ \\
\hline Elbow pain & $117(55.7)$ & $173(82.4)$ \\
\hline Wrist pain & $88(41.9)$ & $163(77.6)$ \\
\hline Upper back pain & $23(11.0)$ & $23(11.0)$ \\
\hline Lower back pain & $107(51.0)$ & $117(55.7)$ \\
\hline Knee pain & $71(33.8)$ & $97(46.2)$ \\
\hline Hip pain & $0(0)$ & $10(4.8)$ \\
\hline Ankle pain & $1(0.5)$ & $5(2.4)$ \\
\hline
\end{tabular}

* Multiple responses present

Table 5: Multivariate models of predictors of musculoskeletal disorders among study subjects

\begin{tabular}{|c|c|c|c|c|}
\hline Variables & & Model 1 & Model 2 & Model 3 \\
\hline Intercept & & -1.867 & -5.371 & -1.638 \\
\hline \multirow{7}{*}{$\begin{array}{l}\text { Socio-demographic } \\
\text { variables }\end{array}$} & Age & *1.151(1.088-1.217) & *1.172(1.096-1.253) & $1.036(0.907-1.184)$ \\
\hline & Socio-econo & status & & \\
\hline & $\mathrm{BPL}$ & $0.793(0.201-3.133)$ & $1.119(0.251-5.000)$ & $0.606(0.032-11.327)$ \\
\hline & APL & 1.00 (Reference) & 1.00 (Reference) & 1.00 (Reference) \\
\hline & Altitude & & & \\
\hline & $<500 \mathrm{~m}$ & ${ }^{*} 0.116(0.029-0.468)$ & ${ }^{*} 0.107(0.023-0.509)$ & $0.595(.029-12.016)$ \\
\hline & $>=500 \mathrm{~m}$ & 1.00 (Reference) & 1.00 (Reference) & 1.00 (Reference) \\
\hline \multirow{7}{*}{ Physical variables } & BMI & & & \\
\hline & Normal & & 1.00 (Reference) & 1.00 (Reference) \\
\hline & Underweight & & $1.007(0.181-5.590)$ & $3.404(0.220-52.584$ \\
\hline & Overweight & & $7.075(0.825-60.670)$ & $23.216(0.816-660.192$ \\
\hline & Pallor & & & \\
\hline & Absent & & 1.00 (Reference) & 1.00 (Reference) \\
\hline & Present & & $1.025(0.241-4.361)$ & $2.867(0.280-29.391)$ \\
\hline \multirow{5}{*}{ Ergonomic variables } & Duration in $\mathrm{pr}$ & nt job & & $1.230(0.940-1.610$ \\
\hline & Average work & hours per day & & $0.871(0.164-4.636)$ \\
\hline & Last working & harvest & & ${ }^{*} 0.923(0.857-0.994)$ \\
\hline & Number of ep & des of work-related & & $1.658(0.835-3.295)$ \\
\hline & REBA score & & & $1.895(0.887-4.047)$ \\
\hline
\end{tabular}

Table 6: Model statistics for the three predictive models

\begin{tabular}{|c|c|c|c|c|c|c|c|}
\hline & \multicolumn{3}{|c|}{ Omnibus Tests of Model Coefficient } & \multirow{2}{*}{$\begin{array}{c}\text { Hosmer } \\
\text { Lemeshow }\end{array}$} & \multirow{2}{*}{$\begin{array}{c}-2 \text { Log } \\
\text { Likelihood }\end{array}$} & \multirow{2}{*}{$\begin{array}{c}\text { Cox \& Snell } \\
\text { R Square }\end{array}$} & \multirow{2}{*}{$\begin{array}{c}\text { Nagelkarke } \\
\text { pseudo } R \\
\text { square } \\
\end{array}$} \\
\hline & Chi-square & df & P value & & & & \\
\hline Model 1 & 44.747 & 3 & 0.000 & 0.975 & 68.387 & 0.192 & 0.461 \\
\hline Model 2 & 50.698 & 6 & 0.000 & 0.852 & 62.435 & 0.214 & 0.515 \\
\hline Model 3 & 82.344 & 11 & 0.000 & 0.714 & 30.789 & 0.324 & 0.779 \\
\hline
\end{tabular}




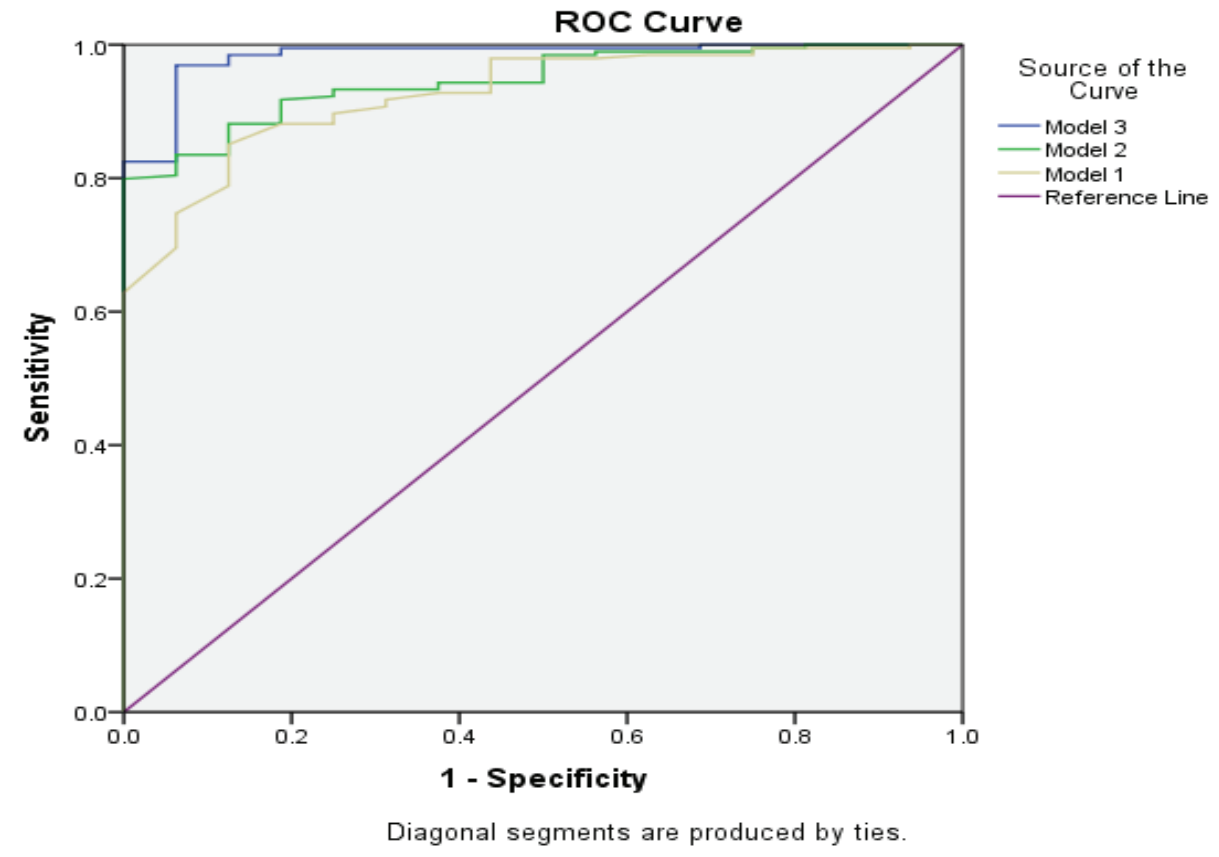

Figure 1: ROC curve showing the three predictive models

\begin{tabular}{cc}
\hline \multicolumn{2}{c}{ Area under the curve } \\
\hline Test Result Variable & Area \\
\hline Model 1 & 0.927 \\
\hline Model 2 & 0.946 \\
\hline Model 3 & 0.984 \\
\hline
\end{tabular}

\section{Discussion}

The women work in hilly undulating terrains of tea gardens of Darjeeling. The work includes plucking tea, carrying the load on their back up to the unloading point, waiting for their turn for unloading. On an average each woman collects about $23-28 \mathrm{~kg}$ of tea leaves depending upon the season of the year.

There are several studies conducted among different occupational groups regarding WRMSDs. The prevalence of lower back pain in commercial vehicle drivers in Malaysia, ${ }^{13}$ professional bus drivers in Israel, ${ }^{14}$ farmers in Ireland, ${ }^{15}$ secondary school teachers in Saudi Arabia ${ }^{16}$ and video display terminal users in Kolkata ${ }^{17}$ was $60.4 \%, 45.4 \%, 56 \%, 79.17 \%$ and $90.78 \%$ respectively. Thus, it can be inferred that the WRMDs is a common phenomenon but the pattern of it depends on the occupation. It was seen in a systematic review by Osbore et al. that the prevalence of MSD was more in farmers than in non-farmers and lower back pain was the most common region followed by the upper and lower extremities. ${ }^{18}$
The prevalence of WRMDs for the past 12 months was $92.4 \%$ in our study as compared with $11.52 \%$ in Dibrugarh, $7.08 \%$ in Delhi and $9.53 \%$ in Jodhpur in the general population as obtained from a multi-centric study by ICMR about epidemiology of musculoskeletal disorders in India. ${ }^{11}$ In a study done at tea garden of Tamil Nadu and palm oil plantation in Malaysia the prevalence of MSD in past 12 months were $83.6 \%$ and $93 \%$ respectively. ${ }^{7,12}$ Thereby, this increased prevalence can be attributed to the pattern and conditions of work done by the plantation workers as compared to the general population.

In our study, upper extremities were the most affected body part. Elbow pain was commonest in both past 7 days $(55.7 \%)$ and past 12 months (82.4\%). Elbow pain and low back pain seems to be more chronic with high prevalence in both past 7 days and past 12 months duration periods. While in a study in a single tea garden in Tamil Nadu, the past 12 months and 7 days prevalence of pain was highest in the shoulder and lower back, respectively. ${ }^{7}$ Another study among workers of a palm plantation, the highest prevalence was of low 
back pain. ${ }^{12}$ The heavy loads carried by tea plantation women and standing for long hours with the weight in undulating difficult terrains of tea gardens of Darjeeling affects their spines leading to chronicity of low back pain. The repeated hand movements of plucking the tea with poor job rotations and less intervening rest periods leads to increased strain on elbow, wrist and shoulder joints leading to their increased WRMSDs in these regions.

The socio-demographic risk factors identified to be attributing to WRMSD are increased age, working in high altitude and poor socio-economic status. In this study, most of the women pluckers aged above 40 years were from BPL families. It signifies lack of periodic health check-ups and social security, as a person with chronic pain must attend her regular work to meet the family expenses. High altitude and rough terrains are part of tea garden cultivation and the women pluckers working with loads over their spine in a difficult posture (as seen in the REBA worksheet) assimilates further assault to the musculoskeletal system resulting in a chronic pain. Tea-plucking women workers adopt static as well as dynamic posture for a long duration (8-10hours/day) reduces blood flow, further deplete nutrients, and lead to a build-up of metabolic waste in their back. Thus, the spinal load is increased which may be another cause of their reduced back strength. Raised BMI is the physical factor identified for WRMSDs among tea garden workers. Overweight, although found in a small percentage of workers further increases the load on the spine culminating in low back pain while under-weight women are more prone for symptoms associated with fibromyalgia. Pallor when coupled with all those factors further causes poor nutrients and poor oxygen delivery to muscles involved in maintaining posture and performing work thus aggravating their symptoms. ${ }^{19}$ The positive association between prevalence and age, poor socio-economic, altitude and nutritional status means that musculoskeletal disorders are likely to be an increasing public health challenge in the future.

The duration in present job, average working hours per day, last working day harvest, number of episodes of work-related injury in past 1 year and REBA score were the ergonomic risk factors associated with WRMSDs. The findings of our study imply that that the respondents were working in a poor posture and there could be a risk of injury as well as deterioration of their muscle \& bone health from work posture. The reasons for this need to be investigated further by occupational therapist and locally feasible changes should be brought about soon to prevent further injury \& restore health \& well-being of the tea workforce of India. A study on Dutch agricultural workers had similar findings with respect to age, BMI and increased workload. ${ }^{20}$

Regarding the results from the REBA analysis, our study showed that the work of tea plucking and carrying the loads were accomplished with bad postures like another study done on Garo women working in tea gardens of Meghalaya, India and also in workers of other industries like dairy farming in Iran. ${ }^{21,22}$

\section{Limitations}

The responses may be subjective or guarded which is considered as a limitation. Workers with recent episodes of MSD will remember the events much better and hence can affect the response to the questionnaire, paving way for recall bias.

\section{Conclusion}

The study revealed that age, nutrition, altitude coupled with ergonomic risk factors were found to be important predictors of work-related musculoskeletal disorders. Thus, the modifiable risk factors that is ergonomic factors needs to be intervened at the earliest because it has two distinct implications, it hampers the quality of life of the workers by increasing their plight of pain on the one hand and on the other hand it may increase sickness absenteeism and leads to diminished productivity in tea plantation industry.

Provision of regular health check-ups, revision of wages system which in most cases is based on weightrate system, ergonomic mechanised assistance in tea plucking, periodic evacuation of the harvest loads and reducing the distance between the plucking area and the evacuation complex can reduce this proportion of musculoskeletal disorders. Tea gardens has an array of job from working in tea factories, working in garden, working in manure sections, pesticides section to office job. If proper job rotation can be done for the workers with provisions of plucking job for a few hours each day followed by other less strenuous job in latter part, that may help dissipate the toxic metabolites from the spinal muscles that accumulates from the drudgery. Locally available \& feasible technologies such as adjustable strap to support the head for the tea-plucking basket while carrying the load in the hilly terrain along with some personnel protective equipment for fingers like rubber finger cots and finger stalls should be 
introduced. As per Plantation Labour Act, India, 1951, the periods of work of adult workers each day shall be so fixed that no period shall exceed fifty-four hours per week with provisions of a weekly holiday and for adolescents it is fixed at forty-eight hours per week. ${ }^{23}$ These modifications if followed may go a long way in reducing sickness absenteeism and increasing productivity.

\section{Acknowledgements}

The authors would like to acknowledge the ANM, ASHA and health supervisors of all the 9 blocks of Darjeeling for their support during data collection. The Chief Medical Officer of Health $(\mathrm{CMOH})$, Darjeeling and the Management of all the 30 tea gardens also deserve mention for their continued support and logistic help with the study.

\section{References}

1. Socioeconomic condition among women workers in plantation industry;2008-2009; a report by Government of India, Ministry of Labour and Employment, Labour Bureau, Chandigarh. [accessed 2020 Jan]

2. Poudel K. Orthodox Tea Production and Its Contribution in Nepal. TTP [Internet]. 9 Nov.2014 [cited 5Apr.2021];8:34-2. Available from: https://www. nepjol.info/index.php/TTP/article/view/11510.

3. Tea Statistics. Available from: Indian brand equity foundation project. Available from: https://www. teacoffeespiceofindia.com/tea/tea-statistics [accessed 2020 Jan].

4. PunnettL, WegmanDH. Work-related musculoskeletal disorders: the epidemiologic evidence and the debate. Journal of electromyography and kinesiology. 2004 Feb 29 [accessed 2020 Jan];14(1):13-23.

5. Podniece Z. Work-relatedmusculoskeletal disorders: Prevention report. 1st ed. Luxembourg: European Agency for Safety and Health at Work; 2008 [accessed 2020 Jan].

6. Lwanga LK, Lemeshow S.Sample size determination in health studies- A practical Manual. World Health Organisation, Geneva. 1991[accessed 2020 Jan]:23. Available from: lemeshow_samplesize.pdf.

7. Vasanth D, Ramesh N, Fathima FN, Fernandez R, Jennifer S, Joseph B. Prevalence, pattern, and factors associated with work-related musculoskeletal disorders among pluckers in a tea plantation in Tamil Nadu, India. Indian journal of occupational and environmental medicine. 2015 Sep [accessed 2020 Jan];19(3):167.

8. Woolf AD, Pfleger B. Burden of major musculoskeletal conditions. Bulletin of the World Health Organization. 2003 [accessed 2020 Jan] ;81:646-56.

9. Kuorinka I, Jonsson B, Kilbom A, Vinterberg $H$, Biering-Sorensen F, Andersson G, Jorgensen K. Standardised Nordic questionnaires for the analysis of musculoskeletal symptoms. Applied ergonomics. 1987 Sep 1[accessed 2020 Jan];18(3):233-7.

10. Hignett S, McAtamney L. Rapid entire body assessment (REBA). Applied ergonomics. 2000 Apr 3;31(2):201-5.

11. Sharma R. Epidemiology of musculoskeletal conditions in India, New Delhi. India: Indian Council of Medical Research (ICMR). 2012.

12. Ng YG, Tamrin SB, Yik WM, Yusoff IS, Mori I. The prevalence of musculoskeletal disorder and association with productivity loss: a preliminary study among labour intensive manual harvesting activities in oil palm plantation. Industrial health. 2014;52(1):7885.

13. Tamrin SB, Yokoyama K, Jalaludin J, Aziz NA, Jemoin $\mathrm{N}$, Nordin $\mathrm{R}$, et al. The association between risk factors and low back pain among commercial vehicle drivers in peninsular Malaysia: A preliminary result. Ind Health. 2007;45:268-78.

14. Alperovitch-Najenson D, Santo $Y$, Masharawi $Y$, Katz-Leurer M, Ushvaev D, Kalichman L. Low back pain among professional bus drivers: Ergonomic and occupational-psychosocial risk factors. Isr Med Assoc J. 2010;12:26-31.

15. Osborne A, Blake C, McNamara J, Meredith D, Phelan J, Cunningham C. Musculoskeletal disorders among Irish farmers. Occup Med (Lond). 2010;60:598-603.

16. Darwish MA, Al-Zuhair SZ. Musculoskeletal pain disorders among secondary school Saudi female teachers. Pain Res Treat. 2013;2013:878570.

17. Molina Aragonés JM, Forns Carbonell J, Rodriguez Moreno JM, Vidiella S, Manuel J, López Pérez C. Systematic review on ocular-visual and musculoskeletal alterations associated with working with data display screens. Medicine and Occupational Safety. 2017 Jun; 63 (247): 167-205.

18. Osbore A, Blake C, Fullen BM, Meredith D, Phelan $\mathrm{J}$, McNamara J, et al. Prevalence of musculoskeletal disorders among farmers: A systematic review. Am J Ind Med. 2012;55:143-58.

19. Si H, Wang C, Jin Y, Tian X, Qiao X, Liu N, et al. Prevalence, factors, and health impacts of chronic pain among community-dwelling older adults in 
China. Pain Management Nursing. 2019 Aug 1;20(4):365-72.

20. Hartman E, Vrielink O, Huub HE, Huirne R, Metz JH. Risk factors for sick leave due to musculoskeletal disorders among self-employed Dutch farmers: A case- control study. American journal of industrial medicine. 2006 Mar 1;49(3):204-14.

21. Marak TR, Bhagat $D$, Borah S. Musculoskeletal disorders of agro women workers engaged in teaplucking activity: An ergonomic analysis. Indian Journal of Occupational and Environmental Medicine. 2020 May; 24(2):60.
22. Taghavi SM, Mokarami H, Ahmadi O, Stallones L, Abbaspour A, Marioryad H. Risk factors for developing work-related musculoskeletal disorders during dairy farming. The international journal of occupational and environmental medicine. 2017 Jan [ accessed 2021 Mar];8(1):39.

23. Plantation Labour Act, India, 1951. Available from: https://labour.gov.in/sites/default/files/The-PlantationLabour-Act-1951.pdf [accessed 2021 Mar] 